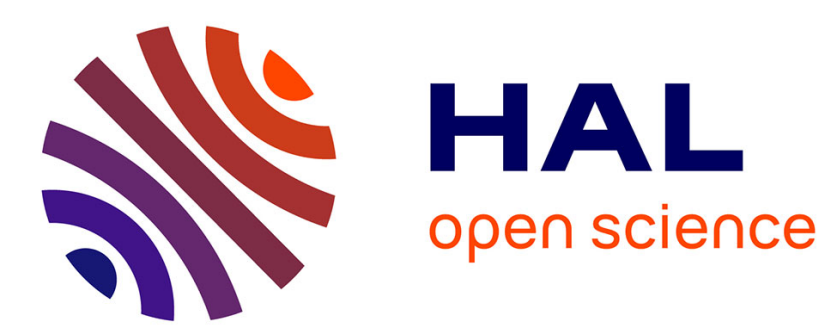

\title{
Quantitative HHV-6B antigenemia test for the monitoring of transplant patients
}

R. Loginov, T. Karlsson, K. Höckerstedt, D. Ablashi, I. Lautenschlager

\section{To cite this version:}

R. Loginov, T. Karlsson, K. Höckerstedt, D. Ablashi, I. Lautenschlager. Quantitative HHV-6B antigenemia test for the monitoring of transplant patients. European Journal of Clinical Microbiology and Infectious Diseases, 2010, 29 (7), pp.881-886. 10.1007/s10096-010-0923-1 . hal-00587606

\section{HAL Id: hal-00587606 https://hal.science/hal-00587606}

Submitted on 21 Apr 2011

HAL is a multi-disciplinary open access archive for the deposit and dissemination of scientific research documents, whether they are published or not. The documents may come from teaching and research institutions in France or abroad, or from public or private research centers.
L'archive ouverte pluridisciplinaire HAL, est destinée au dépôt et à la diffusion de documents scientifiques de niveau recherche, publiés ou non, émanant des établissements d'enseignement et de recherche français ou étrangers, des laboratoires publics ou privés. 


\title{
Quantitative HHV-6B antigenemia test for the monitoring of transplant patients
}

\author{
R. Loginov • T. Karlsson • K. Höckerstedt • D. Ablashi • \\ I. Lautenschlager
}

Received: 16 December 2009/Accepted: 27 March 2010/Published online: 21 April 2010

(C) Springer-Verlag 2010

\begin{abstract}
Human herpesvirus-6 (HHV-6) infection, mostly caused by variant $\mathrm{B}$, is common after transplantation. Here, we report a new modified method using an HHV-6B glycoprotein IgG antibody, OHV-3, and attempt to quantify the HHV-6 antigenemia after liver transplantation. Twentyfour liver transplant recipients were frequently monitored by the HHV-6 antigenemia test, which detects the HHV-6B virion protein in peripheral blood mononuclear cells (PBMC). HHV-6B antigens were now retrospectively demonstrated using a glycoprotein OHV-3 IgG antibody in the immunoperoxidase staining from the same specimens and quantified as positive cells/10,000 PBMC. The results were confirmed and quantified by DNA hybridization in situ. Altogether, 206 blood specimens were analyzed. During the first six months, HHV-6 antigenemia was
\end{abstract}

R. Loginov $\cdot$ T. Karlsson $\cdot$ I. Lautenschlager

Department of Virology, HUSLAB,

Helsinki University Hospital and University of Helsinki,

FIN-00290 Helsinki, Finland

R. Loginov $\cdot$ T. Karlsson $\cdot$ K. Höckerstedt $\cdot$ I. Lautenschlager Department of Surgery, Division of Transplantation and Liver Surgery, and Transplant Unit Research Laboratory, Helsinki University Hospital and University of Helsinki, FIN-00290 Helsinki, Finland

D. Ablashi

HHV-6 Foundation,

277 San Ysidro Road,

Santa Barbara, CA, USA

R. Loginov $(\bowtie)$

Transplant Unit Research Laboratory,

Helsinki University Hospital,

Meilahti, P-Floor PL 340,

FIN-00029 HUS Helsinki, Finland

e-mail: raisa.loginov@hus.fi detected in 17/24 (71\%) recipients by using the HHV-6B virion antibody. In total, $37 \%(77 / 206)$ of specimens were positive with the virion antibody and $39 \%(78 / 201)$ by the OHV-3 antibody. The peak number of OHV-3-positive cells in the PBMC varied from 5 to $750 / 10,000$ (mean 140/ $10,000)$. The OHV-3 antibody was useful to quantify the HHV-6B antigenemia. The findings of the HHV-6B quantitative antigenemia using the OHV-3 antibody correlated well with the previous qualitative HHV-6 antigenemia assay, and can be used as an alternative quantitative method in the monitoring of HHV-6 in transplant patients.

Human herpesvirus-6 (HHV-6) is a ubiquitous virus which is widespread throughout the world [1]. Two major subgroups of HHV-6 have been identified, variants A and $\mathrm{B}$, of which variant $\mathrm{B}$ is the most common. Like other herpesviruses, HHV-6 can remain in a latent or persistent state in the host after primary infection and can reactivate under immunosuppression. HHV-6 has been recognized as a potentially significant pathogen in both solid organ and stem cell transplant recipients [2-4]. HHV-6 infections, mostly caused by variant $\mathrm{B}$, occur in the early posttransplant period, usually within the first four weeks after transplantation. In liver transplantation, HHV-6 reactivations are mostly asymptomatic, but clinical symptoms such as encephalitis, hepatitis, or graft dysfunction have been described [2-4]. The most sensitive techniques for the detection of HHV-6 infection are polymerase chain reaction (PCR)-based methods [4]; both qualitative and quantitative methods have been described. However, by PCR methods, it is not always possible to differentiate between latent and active viral infections. On the other hand, there is a recognized phenomenon of HHV-6 integration into host cell DNA [5], and such integration is characterized by a 
high viral load in the blood using quantitative PCR methods. The detection of cellular HHV-6 DNA by in situ hybridization in peripheral blood mononuclear cells (PBMC) of liver transplant patients [6] has shown a good correlation with the HHV-6 antigenemia test and may be used in the monitoring of those patients. The HHV-6 antigenemia test, which detects the viral antigens in PBMC by monoclonal antibodies and immunoperoxidase staining, has been used to demonstrate an active HHV-6 infection in transplant patients $[7,8]$. The HHV-6 antigenemia test was demonstrated to correlate with quantitative PCR [9], but the method itself is rather qualitative than quantitative. The HHV-6 antigenemia assay indicates the presence of an active infection and also enables to differentiate between HHV-6A and HHV-6B infections [7]. The purpose of this retrospective study is to improve the HHV-6 antigenemia test so that it will be possible to quantify the positive cells.

Twenty-four consecutive adult transplant recipients, who underwent liver transplantation during the year 2006, were frequently monitored for HHV-6 infection up to six months post-transplantation. A total of 206 blood specimens were analyzed (mean 8.5 samples/patient, range 5-13). For the HHV-6 antigenemia test, PBMC were isolated by FicollPaque density gradient centrifugation and cytocentrifuged onto microscope slides. In parallel, slides were acetonefixed and stored at $-70^{\circ} \mathrm{C}$ for later examination. HHV- 6 infections were originally diagnosed by the HHV-6 antigenemia test in PBMC using indirect immunoperoxidase staining with a monoclonal antibody against HHV-6B (MAB8535, Chemicon, Inc., Temecula, CA), a 101-kDa virion protein as described earlier [7]. Retrospectively, the quantitative detection of HHV-6 antigenemia was performed from the same specimens using the HHV-6Bspecific OHV-3 IgG antibody (obtained from the HHV-6 Foundation Reagents Repository), which detects $98-\mathrm{kDa}$ and 92-kDa glycoproteins of HHV-6 [10]. The number of OHV-3-positive cells was counted per 10,000 PBMC. In the event of discrepancies between the results, the specimens were further analyzed by using a third monoclonal antibody (Ref-11-242, Argene Biosoft, Varilhes, France), which detects both HHV-6 variants A and B. HHV-6 DNA was also retrospectively analyzed from 104 available PBMC specimens from 16 patients by in situ hybridization using a biotinylated oligoprobe mixture (Qiagen, Cologne, Germany) detecting both HHV-6A and B variants [6]. The HHV-6 in situ hybridization findings were quantified as DNA-positive cells/10,000 PBMC and correlated to the antigenemia results.

HHV-6 antigenemia was detected in 17/24 (71\%) recipients within the first six months after liver transplantation using the HHV-6B virion antibody (MAB8535, Fig. 1a). The HHV-6 antigenemia appeared during the first three weeks after transplantation in all cases. All patients,

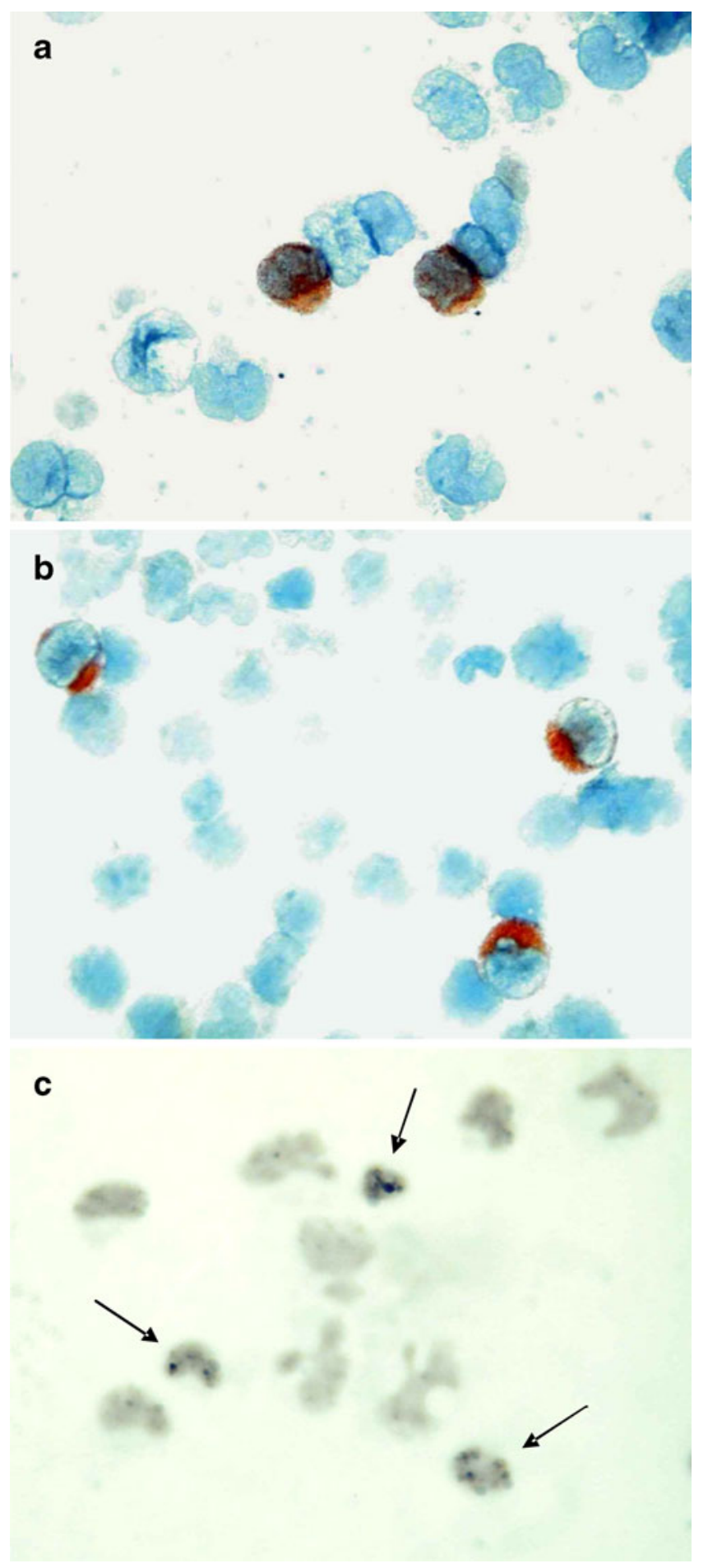

Fig. 1 HHV-6-positive lymphocytes demonstrated by immunoperoxidase staining using (a) the HHV-6B virion antibody (MAB8535) and (b) the glycoprotein antibody OHV-3. Note the intense cytoplasmic staining by the glycoprotein antibody OHV-3. (c) HHV-6 DNApositive cells (arrows) demonstrated by in situ hybridization (original magnification $\times 1,000)$ 
except for one with a weak positivity (patient number 22), also demonstrated HHV-6 antigen by the OHV-3 antibody, and these findings were quantified as positive cells $/ 10,000$ PBMC (Table 1). The positive staining by the OHV-3 antibody was clear, and was seen in the cytoplasma only (Fig. 1b). Altogether, 37\% (77/206) of specimens were positive with the MAB 8535 antibody and 39\% (78/201) of specimens with the OHV-3 antibody. The peak number of OHV-3-positive cells varied from 5 to $750 / 10,000$ PBMC, and the mean was $140 / 10,000$ PBMC.

One recipient (patient number 18) was HHV-6 antigenemia-negative by both antibodies (MAB8535 and OHV-3) during the follow-up. Six patients had discrepancies between the results and the specimens of these patients were then further analyzed using a third antibody detecting both HHV-6A and HHV-6B variants. These six patients were all negative by MAB8535 during the followup, but positive by both OHV-3 antibody and the one detecting both HHV-6A and B. This finding suggests that, when the OHV-3 antibody is directed against other viral proteins, it could pick up an antigen which is not detectable by the virion protein antibody. However, double infection could not be excluded in these patients.

HHV-6 DNA in situ hybridization was performed to confirm the antigenemia findings. Concurrent HHV-6 DNA was detected in 14/15 patients who were antigen-positive by either or both of the two HHV-6 antibodies, MAB8535 and OHV-3 (Table 1). The positive reaction of the in situ hybridization was seen as a spotted, dark nuclear staining (Fig. 1c). One patient who showed faint staining by MAB8535 antibody (patient number 22), was negative by OHV-3 antibody and had no HHV-6-DNA. The number of HHV-6 DNA-positive cells was counted per 10,000 PBMC. The number of HHV-6 DNA-positive cells varied from 8 to 2,920/10,000 PBMC (mean 559). The HHV-6 DNA findings correlated well with the antigenemia findings. Two patients (numbers 1 and 5), who had discrepancies between the results of the two used antibodies, both showed HHV-6 DNA in their mononuclear cells.

In 7/17 patients, HHV-6 antigens were also demonstrated in the liver biopsies associated with graft dysfunction. In five cases, intragraft HHV-6 was found together with mild to moderate acute rejection, and the patients were treated with high doses of steroids. The other two patients with HHV-6-positive biopsy and graft dysfunction recovered without any treatment. The mean peak number of OHV-3positive cells $(133 / 10,000)$ in patients with hepatic infection did not differ to those without $(140 / 10,000)$. Four patients developed cytomegalovirus (CMV) infection during the follow-up and they were treated with intravenous ganciclovir. However, antiviral treatment was started on all of these patients after the peak of the HHV-6 episode was already over. In other patients, HHV-6 antigenemia lasted usually for some weeks without any specific symptoms and subsided slowly without treatment.

An active HHV-6 infection can be diagnosed from the peripheral blood specimens of liver transplant patients by detection of the virus-specific antigens in mononuclear cells [7]. The method has been shown to correlate with wholeblood quantitative PCR [9]. However, the previous HHV-6 antigenemia test is rather qualitative than quantitative, because no obvious changes can be seen in the number of antigen-positive cells but instead in the intensity of staining in the PBMC. In this study, we used the HHV-6B OHV-3 monoclonal antibody and quantified the number of positive PBMC during the follow-up of the first six months after adult liver transplantation. The intensity of the positive signal by OHV-3 was clear-cut and the number of positive cells was easy to quantify. The OHV-3 monoclonal antibody made it possible to quantify the HHV-6 load from the PBMC of transplant patients, but the peak values of OHV-3-positive cells varied widely. The same kind of variation was also seen in the HHV-6 DNA in situ assay, where we quantified HHV-6 DNA-positive mononuclear cells after liver transplantation [6]. The HHV-6B-specific OHV-3 antibody results correlated quite well with the HHV6 (MAB8535) antigenemia findings in most cases. However, there was discordance between the results in some cases, especially in the case of faint staining. The OHV-3 antibody seemed to be more sensitive in detecting HHV-6B antigenemia. When the antigenemia results were compared to those of HHV-6 DNA in situ hybridization, specimens positive by either one or both of the HHV-6 antibodies MAB8535 and OHV-3, good correlation was found.

Six patients had a discrepancy in the results of the two HHV-6B antibodies used. The specimens of these six patients were further analyzed and four patients demonstrated clear positive findings by a third antibody detecting both A and B variants. Thus, those patients had either double infection or the two antibodies used may react with different epitopes of the viral antigen. Two patients (numbers 1 and 5) who had discrepancies between the results of the HHV-6 antibodies were found to be positive by in situ hybridization.

The quantitative HHV-6 antigenemia assay provides an alternative possibility to quantify HHV-6 infection. This method might be useful in the differentiation between a latent and an active infection. In the case of HHV-6 integration, where quantitative PCR methods show high copy numbers in the blood, the demonstration of HHV-6 proteins could be more diagnostic. On the other hand, due to the retrospective nature of the present study, no plasma or serum material was available from our patients to perform PCR.

In liver transplant patients, most HHV-6 reactivations are asymptomatic. In our patients, no other specific symptoms but graft dysfunction was associated with HHV-6 anti- 
Table 1 The follow-up of HHV-6 antigenemia and DNA in situ hybridizations of 24 recipients after liver transplantation

\begin{tabular}{|c|c|c|c|c|c|c|c|c|c|c|c|}
\hline Specimens & MAB8535 & OHV-3 & ISH & Specimens & MAB8535 & OHV-3 & ISH & Specimens & MAB8535 & OHV-3 & ISH \\
\hline Patient 2 & & & & Patient 11 & & & & Patient 17 & & & \\
\hline 1 & pos & 200 & nd & 1 & neg & 0 & nd & 1 & pos & 80 & 60 \\
\hline 2 & pos & 50 & 200 & 2 & $+/-$ & 0 & nd & 2 & neg & 0 & neg \\
\hline 3 & pos & 30 & nd & 3 & neg & 20 & nd & 3 & neg & 0 & neg \\
\hline 4 & pos & 30 & nd & 4 & neg & nd & nd & 4 & neg & 0 & neg \\
\hline 5 & pos & 30 & nd & 5 & neg & 0 & nd & 5 & neg & 0 & neg \\
\hline 6 & pos & 10 & nd & 6 & neg & 0 & nd & 6 & neg & 0 & neg \\
\hline 7 & $+/-$ & 5 & 640 & 7 & neg & nd & nd & 7 & neg & 0 & neg \\
\hline 8 & $+/-$ & 20 & 35 & 8 & neg & 20 & nd & Patient 18 & & & \\
\hline 9 & $+/-$ & 0 & 75 & 9 & neg & 0 & nd & 1 & neg & 0 & neg \\
\hline 10 & $+/-$ & 5 & 72 & Patient 12 & & & & 1 & neg & 0 & neg \\
\hline 11 & pos & nd & nd & 1 & $+/-$ & 10 & 1,170 & 2 & neg & 0 & neg \\
\hline 12 & pos & 100 & 70 & 2 & neg & 0 & neg & 3 & neg & 0 & neg \\
\hline 13 & pos & 0 & nd & 3 & neg & 0 & neg & 4 & neg & 0 & neg \\
\hline Patient 3 & & & & 4 & $+/-$ & 40 & 880 & 5 & neg & 0 & neg \\
\hline 1 & pos & 20 & nd & 5 & neg & 20 & 350 & 6 & neg & 0 & neg \\
\hline 2 & pos & 50 & nd & 6 & neg & 0 & neg & 7 & neg & 0 & neg \\
\hline 3 & $+/-$ & 50 & nd & 7 & neg & 0 & neg & 8 & neg & 0 & neg \\
\hline 4 & $+/-$ & 15 & 1,100 & 8 & neg & 0 & neg & 9 & neg & 0 & neg \\
\hline 5 & neg & 5 & nd & 9 & neg & 60 & 330 & 10 & neg & 0 & neg \\
\hline 6 & neg & 100 & nd & Patient 13 & & & & 11 & neg & 0 & neg \\
\hline 7 & neg & 20 & nd & 1 & $+/-$ & 5 & nd & Patient 20 & & & \\
\hline 8 & neg & 5 & nd & 2 & $+/-$ & 0 & nd & 1 & pos & 5 & 55 \\
\hline 9 & neg & 0 & neg & 3 & $+/-$ & 0 & nd & 2 & pos & 0 & 600 \\
\hline 10 & neg & 0 & neg & 4 & $+/-$ & 50 & nd & 3 & pos & 10 & 170 \\
\hline 11 & neg & 0 & neg & 5 & $+/-$ & 0 & nd & 4 & neg & 0 & neg \\
\hline 12 & neg & 0 & neg & 6 & neg & 10 & 880 & 5 & neg & 0 & neg \\
\hline Patient 4 & & & & 7 & neg & 0 & nd & 6 & neg & 5 & nd \\
\hline 1 & neg & 0 & nd & 8 & neg & 30 & nd & 7 & pos & 50 & 850 \\
\hline 2 & pos & 40 & 2,000 & 9 & $+/-$ & 120 & 480 & 8 & $+/-$ & 50 & 40 \\
\hline 3 & neg & 0 & neg & Patient 14 & & & & 9 & $+/-$ & 10 & 40 \\
\hline 4 & neg & 0 & neg & 1 & $+/-$ & 0 & nd & 10 & $+/-$ & 0 & neg \\
\hline 5 & neg & 0 & neg & 2 & pos & 0 & nd & 11 & neg & 0 & neg \\
\hline 6 & neg & 0 & neg & 3 & pos & 0 & nd & Patient 21 & & & \\
\hline 7 & neg & 0 & neg & 4 & $+/-$ & 5 & nd & 1 & pos & 130 & 110 \\
\hline 8 & neg & 0 & neg & 5 & $+/-$ & 0 & nd & 2 & $+/-$ & 0 & neg \\
\hline Patient 6 & & & & 6 & neg & 0 & nd & 3 & neg & 0 & neg \\
\hline 1 & neg & 0 & nd & 7 & neg & 0 & nd & 4 & neg & 0 & neg \\
\hline 2 & $+/-$ & 20 & nd & Patient 15 & & & & 5 & neg & 0 & neg \\
\hline 3 & $+/-$ & 10 & nd & 1 & pos & 200 & nd & 6 & neg & 0 & neg \\
\hline 4 & pos & 5 & nd & 2 & pos & 50 & nd & 7 & neg & 0 & neg \\
\hline 5 & pos & 5 & nd & 3 & pos & 5 & nd & 8 & neg & 0 & neg \\
\hline 6 & $+/-$ & 0 & nd & 4 & pos & 5 & nd & Patient 22 & & & \\
\hline 7 & neg & 0 & nd & 5 & $+/-$ & nd & nd & 1 & $+/-$ & 0 & neg \\
\hline 8 & neg & 0 & nd & 6 & pos & nd & nd & 2 & $+/-$ & 0 & nd \\
\hline 9 & $+/-$ & 0 & nd & 7 & $+/-$ & 0 & nd & 3 & neg & 0 & neg \\
\hline Patient 9 & & & & 8 & $+/-$ & 0 & nd & 4 & neg & 0 & neg \\
\hline 1 & $+/-$ & 380 & 2,920 & 9 & $+/-$ & 0 & nd & 5 & neg & 0 & neg \\
\hline 2 & neg & 260 & 1,630 & Patient 16 & & & & 6 & neg & 0 & neg \\
\hline
\end{tabular}


Table 1 (continued)

\begin{tabular}{|c|c|c|c|c|c|c|c|c|c|c|c|c|c|}
\hline Specimens & MAB8535 & OHV-3 & ISH & Specimens & MAB8535 & OHV-3 & ISH & \multicolumn{2}{|c|}{ Specimens } & \multicolumn{2}{|c|}{ MAB8535 } & OHV-3 & ISH \\
\hline 3 & neg & 0 & neg & 1 & neg & 0 & neg & 7 & & neg & & 0 & neg \\
\hline 4 & neg & 0 & neg & 2 & $+/-$ & 0 & nd & Patien & & & & & \\
\hline 5 & neg & 0 & neg & 3 & $+/-$ & 0 & neg & 1 & & neg & & 330 & 1,400 \\
\hline 6 & neg & 0 & neg & 4 & neg & 400 & 200 & 2 & & $+/-$ & & 0 & neg \\
\hline Patient 10 & & & & 5 & $+/-$ & 200 & 125 & 3 & & $+/-$ & & 0 & neg \\
\hline 1 & pos & 5 & nd & 6 & neg & 0 & nd & 4 & & $+/-$ & & 40 & 75 \\
\hline 2 & $+/-$ & 100 & nd & 7 & neg & 210 & 980 & 5 & & $+1-$ & & 30 & 80 \\
\hline 3 & $+/-$ & 10 & 8 & & & & & 6 & & neg & & 0 & neg \\
\hline 4 & $+/-$ & 20 & nd & & & & & 7 & & $+/-$ & & 0 & nd \\
\hline 5 & neg & 5 & 116 & & & & & 8 & & neg & & 0 & neg \\
\hline 6 & $+/-$ & 5 & 860 & & & & & 9 & & neg & & 0 & neg \\
\hline 7 & $+/-$ & 0 & 183 & & & & & 10 & & $+1-$ & & 10 & 30 \\
\hline 8 & neg & 0 & nd & & & & & 11 & & neg & & 0 & neg \\
\hline 9 & neg & 0 & nd & & & & & 12 & & neg & & 0 & neg \\
\hline 10 & $+/-$ & 0 & neg & & & & & 13 & & neg & & 0 & neg \\
\hline 11 & $+/-$ & 0 & neg & & & & & & & & & & \\
\hline $\begin{array}{l}\text { Specimens } \\
\text { Patient } 1^{*}\end{array}$ & MAB8535 & $\mathrm{OHV}-3$ & & HHV-6A + B & ISH & $\begin{array}{l}\text { Specimens } \\
\text { Patient } 5^{*}\end{array}$ & MA & 8535 & $\mathrm{OH}$ & $V-3$ & $\mathrm{HH}$ & $-6 A+B$ & ISH \\
\hline 1 & neg & 0 & & neg & nd & 1 & neg & & 10 & & neg & & 24 \\
\hline 2 & neg & 5 & & neg & nd & 2 & neg & & 0 & & neg & & neg \\
\hline 3 & neg & 10 & & pos & 1,850 & 3 & neg & & 5 & & neg & & nd \\
\hline 4 & neg & 0 & & nd & nd & 4 & neg & & 0 & & neg & & neg \\
\hline 5 & neg & 50 & & neg & nd & 5 & neg & & 5 & & pos & & nd \\
\hline 6 & neg & 0 & & $+/-$ & nd & 6 & neg & & 0 & & pos & & nd \\
\hline 7 & neg & 0 & & pos & nd & 7 & neg & & 0 & & $+/-$ & & nd \\
\hline Patient $7 *$ & & & & & & Patient $8^{*}$ & & & & & & & \\
\hline 1 & neg & 750 & & pos & nd & 1 & neg & & 0 & & neg & & nd \\
\hline 2 & neg & 60 & & $+/-$ & nd & 2 & neg & & 10 & & neg & & nd \\
\hline 3 & neg & 680 & & pos & nd & 3 & neg & & 20 & & neg & & nd \\
\hline 4 & neg & 0 & & $+/-$ & nd & 4 & neg & & 0 & & $+/-$ & & nd \\
\hline 5 & neg & 0 & & pos & nd & 5 & neg & & 0 & & neg & & nd \\
\hline 6 & neg & 50 & & $+/-$ & nd & Patient $24 *$ & & & & & & & \\
\hline 7 & neg & 0 & & neg & nd & 1 & neg & & 5 & & $+/-$ & & nd \\
\hline 8 & neg & 50 & & $+/-$ & nd & 2 & neg & & 0 & & $+/-$ & & nd \\
\hline Patient $19 *$ & & & & & & 3 & neg & & 20 & & $+/-$ & & nd \\
\hline 1 & neg & 0 & & neg & nd & 4 & neg & & 0 & & $+/-$ & & nd \\
\hline 2 & neg & 0 & & neg & nd & 5 & neg & & 0 & & $+/-$ & & nd \\
\hline 3 & neg & 0 & & pos & nd & 6 & neg & & 0 & & neg & & nd \\
\hline 4 & neg & 0 & & neg & nd & & & & & & & & \\
\hline 5 & neg & 0 & & pos & nd & & & & & & & & \\
\hline 6 & neg & 5 & & $+/-$ & nd & & & & & & & & \\
\hline 7 & neg & 0 & & neg & nd & & & & & & & & \\
\hline
\end{tabular}

neg $=$ negative staining;pos $=$ strong positive $;+/-=$ faint staining

The OHV-3-positive cells and HHV-6 DNA in situ-positive cells were counted per 10,000 PBMC

*HHV-6 antigenemia and HHV-6 DNA in situ hybridizations after liver transplantation of six patients with different findings withMAB8535, OHV-3, and HHV-6A + B variant specific antibodies 
genemia. However, in most cases of intrahepatic HHV-6, graft dysfunction was obviously due to rejection and only in two cases due to HHV-6. Four patients developed symptomatic CMV infections after the peak of HHV-6 antigenemia. However, correlation between HHV-6 viral load by the quantitative method and the clinical symptoms was difficult because of CMV or concurrent rejections.

In conclusion, the findings of the HHV-6B quantitative antigenemia demonstrated by the OHV-3 antibody correlated well with the previous qualitative HHV-6 antigenemia assay. The glycoprotein antibody OHV-3 made it possible to quantify the number of positive cells better than the previous virion protein antibody, and this monoclonal antibody appeared to be similar in sensitivity in detecting HHV-6 infection. The quantitative HHV-6 antigenemia assay may be used as an alternative test in the monitoring of the viral load of transplant recipients and other patients with suspected HHV-6 infection. However, further investigation of the clinical significance of the HHV-6 antigenemia peaks is necessary.

Acknowledgments We want to acknowledge the support of the HHV6 Foundation for providing the OHV-3 MAB, the hybridoma, which was donated by Prof. K. Yamanishi. The OHV-3 monoclonal antibody is available, free of charge, to other transplantation investigators for research purposes from the HHV-6 Foundation Reagents Repository.

This study was supported by grants from the Sigrid Jusélius Foundation (to K. Höckerstedt and I. Lautenschlager) and the Helsinki University Hospital Research Funds (to I. Lautenschlager).

The authors thank Marjatta Palovaara for the technical assistance and Stephen Venn and Courtney Devin for correcting the English text.

\section{References}

1. De Bolle L, Naesens L, De Clercq E (2005) Update on human herpesvirus 6 biology, clinical features, and therapy. Clin Microbiol Rev 18:217-245

2. Ljungman P, Singh N (2006) Human herpesvirus-6 infection in solid organ and stem cell transplant recipients. J Clin Virol 37 (Suppl 1):S87-S91

3. Zerr DM (2006) Human herpesvirus 6: a clinical update. Herpes 13(1):20-24

4. Abdel Massih RC, Razonable RR (2009) Human herpesvirus 6 infections after liver transplantation. World J Gastroenterol 15 (21):2561-2569

5. Ward KN, Leong HN, Nacheva EP, Howard J, Atkinson CE, Davies NW, Griffiths PD, Clark DA (2006) Human herpesvirus 6 chromosomal integration in immunocompetent patients results in high levels of viral DNA in blood, sera, and hair follicles. J Clin Microbiol 44:1571-1574

6. Loginov R, Härmä M, Halme L, Höckerstedt K, Lautenschlager I (2006) HHV-6 DNA in peripheral blood mononuclear cells after liver transplantation. J Clin Virol 37(Suppl 1):S76-S81

7. Lautenschlager I, Linnavuori K, Höckerstedt K (2000) Human herpesvirus- 6 antigenemia after liver transplantation. Transplantation 69:2561-2566

8. Volin L, Lautenschlager I, Juvonen E, Nihtinen A, Anttila VJ, Ruutu T (2004) Human herpesvirus 6 antigenaemia in allogeneic stem cell transplant recipients: impact on clinical course and association with other beta-herpesviruses. $\mathrm{Br} \mathrm{J}$ Haematol 126:690-696

9. Härmä M, Loginov R, Piiparinen H, Halme L, Höckerstedt K, Lautenschlager I (2005) HHV-6-DNAemia related to CMVDNAemia after liver transplantation. Transplant Proc 37:1230 1232

10. Okuno T, Sao H, Asada H, Shiraki K, Takahashi M, Yamanishi K (1990) Analysis of a glycoprotein of human herpesvirus 6 (HHV6) using monoclonal antibodies. Virology 176(2):625-628 